\title{
Scientific and Technological Trends in the Agroindustrial Field
}

\author{
${ }^{1}$ Juan Manuel Andrade Navia, ${ }^{2}$ Alejandro Orjuela Garzon, ${ }^{3}$ Elias Ramirez Plazas and \\ ${ }^{3}$ Alexander Quintero Bonilla \\ ${ }^{1}$ Corporacion Universitaria Minuto de Dios, Bogota, Colombia \\ ${ }^{2}$ Universidad del Tolima, Ibague, Colombia \\ ${ }^{3}$ Universidad Surcolombiana, Huila, Colombia
}

\begin{abstract}
Scientific and technological management is now imperative for regional and national development, especially, in sectors with social and economic importance. For this reason, this study presents a study of technological surveillance for the agroindustrial sector based on search equations in the Scopus database. Likewise, a plan was defined to carry out the study which contemplates four stages: scientific production, outstanding researchers in scientific production, countries with the largest number of publications and outstanding institutions with scientific production. Finally, the growing trend in research related to the utility of by products and properties of products of agricultural origin was evidenced during the studied decade.
\end{abstract}

Key words: Search equation, agro-industry, technological surveillance, scientific production, database, publications

\section{INTRODUCTION}

The dynamics of international trade has been relevant in determining the productive structures of economic sectors in the vast majority of countries, causing the different productive sectors to constantly rethink at a competitive pace and develop dynamic competences, especially, when there is a significant number of medium and small companies that need to advance technologically (Vargas, 2015). In this regard, recent experiences suggest that a successful way of reacting to this environment is to increase investments in $\mathrm{R}$ and $\mathrm{D}$ for the improvement of products and processes (Sandino-Vargas, 2014).

During the rise of new technologies, trends such as technological surveillance have been imposed as competitiveness strategies to a large extent justified by the volume of relevant information necessary for decision making (Andrade et al., 2015: Palop and Vicente, 1999; Ramirez-Calvo et al., 2013).

Recognizing the potential value of bibliometric analysis (Daim et al., 2006; Lee et al., 2017) many researchers have focused their studies on tools such as datamining (Lee et al., 2014) and patent analysis (Lee et al., 2009).

Technological surveillance (here in after referred to as TS) can be defined as the systematic and organized process of searching, capturing and analyzing information of a technological, commercial, competitive and normative nature nationally and internationally which allows anticipation to clarify the actions through the decisions, passing before by the appropriation and reaching a collective or organizational learning (Du Toit, 2013; Anonymous, 2014).

The application of this methodological model has its foundation and origin in the prospective models that allow the identification of factors of change which will have a direct impact on the strategic planning process. This will define the desired scenario for a company or territory.

The TS is born from the need of organizations to observe their environment and to have the capacity to respond to the changes that occur and that generally affect them. In other words, it is the systematic and organized effort by the company to observe, capture, analyze, accurately disseminate and retrieve information about the facts of the economic, technological, social or commercial environment, relevant to it for being able to imply an opportunity or threat in order to be able to make decisions with less risk and be able to anticipate changes (Pere and Maspons, 2001; Du Toit, 2013; Villarroel et al., 2015).

Although, there are different types of technological surveillance, the present study centers on the advances in scientific and technological production, given that TS is focused on advances in the state of the art and technology available and emerging in any business sector. This allows to identify technologies in decline and guarantee the processes of technology transfer, just as

Corresponding Author: Juan Manuel Andrade Navia, Corporacion Universitaria Minuto de Dios, Bogota, Colombia 
the area of research and development allows to establish the inventive and patentability level of an innovation (Anonymous, 2014).

Thus, the sector can organize surveillance around the information on current and/or potential competitors and of those substitute products, performing an analysis and monitoring of the destination of their investments, products, distribution circuits, response times, type of clients and degree of satisfaction, organization and financial capacity. The value chain of the sector and its participation in said value chain (Porter and Cunningham, 2005). Taking this in consideration, it becomes relevant to know the scientific trends related to agro-industry taking into account that it constitutes a national productive commitment on which the Colombian economy depends and which in recent years has made enormous efforts to implement technology-based developments that allow it to reorient its productive chain towards products with added value. Therefore, aspects such as scientific production, prominent researchers in scientific production, countries with a greater number of publications and outstanding institutions with scientific production will be studied in this study.

\section{MATERIALS AND METHODS}

For the realization of technological surveillance studies, there are several procedures described by recognized researchers. The methodology used for the development of this study is explained (Garcia et al., 2016; Gimenez-Toledo and Roman, 2001).

Construction of the search matrix: The construction of the search matrix is oriented towards the definition of the scope of the study. This is developed jointly by experts and researchers who due to their knowledge and experience, provide key elements to take into account in the development of the search matrix.

Identification of the tools to be used: The main databases that contain information related to the research topic were defined and accessed for the elaboration of this study using.

\section{Scopus}

The largest database of citations and abstracts of peer-reviewed literature: Scientific journals, books and conference proceedings. It has intelligent tools to track, analyze and visualize research, offering an overview of the global production of research in the fields of science, technology, medicine, social sciences as well as thearts and humanities.
Construction of the equations through the use of operators: In the construction of the search equations, both the thesaurus and the Boolean operators were taken into account, estimating a construction of three equations for searching scientific studies and another three for searching for patents. The operators allowed to focus the exploration, linking search terms and defining the relationship between them.

The search equation was (((TITLE-ABS-KEY (agroindustria ) ) or (TITLE-ABS-KEY (agro-industria)) or (TITLE-ABS-KEY (agroindustry)) or (TITLE-ABS-KEY (agro-industrial)) or (TITLE-ABS-KEY (agro-industry)) or (TITLE-ABS-KEY (agribusiness )) or (TITLE-ABS-KEY (agri-food industry)) or(TITLE-ABS-KEY (agroaliment*))) or(TITLE-ABS-KEY (“agri-food sector")) or(TITLE-ABSKEY (agro-food))) AND PUBYEAR>2004

Information analysis: The technology surveillance software used to process the information was Matheo Analyzer. With it, it was possible to obtain accurate manipulation of the flat files exported from each of the databases. The software uses an interface that allows a better visualization and manipulation of the data obtained by generating exchange relationships for data groups.

\section{RESULTS AND DISCUSSION}

Scientific production: The results obtained through the developed search equation show for the period 2005-2016, a total of 7,858 knowledge products related to the area of study and scientific production with a growing trend for the agro-industrial sector (Fig. 1).

The knowledge products include 6,819 scientific articles, 717 documents derived from conferences and 322 book chapters. The related areas of knowledge include agriculture and biological sciences with 3,873 documents, social sciences with 1,799 , environmental sciences with 1,426 , business management and accounting, biochemistry and molecular genetics with 760 . From these thematic areas, the following research trends that mark the evolution of the sector were obtained (Fig. 2).

For the field of agriculture and biological sciences, the three main sub-areas of research are fermentation, food safety and enzymatic activity. The first one highlights the production of biodiesel, ethanol or bioethanol from lignocellulose derived from sugarcane processing plants or other crops. Its main research focus is the development of low-cost equipment as the limitation of lignocellulose processing is the lack of technology accessible to medium and small producers. Another aspect is the recovery of waste based on enzymatic fermentation, ultrasound with Aspergillus japonicus PJ01 and Bacillus subtilis NX-2. 


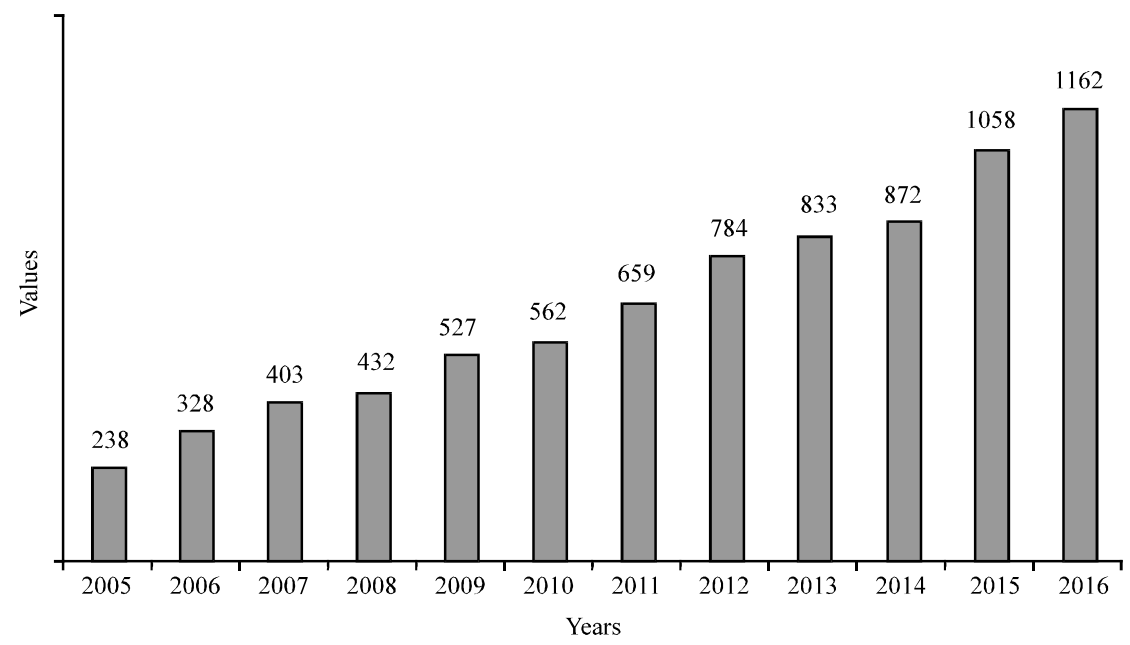

Fig. 1: Scientific production for the agro-industrial sector (2005-2015)

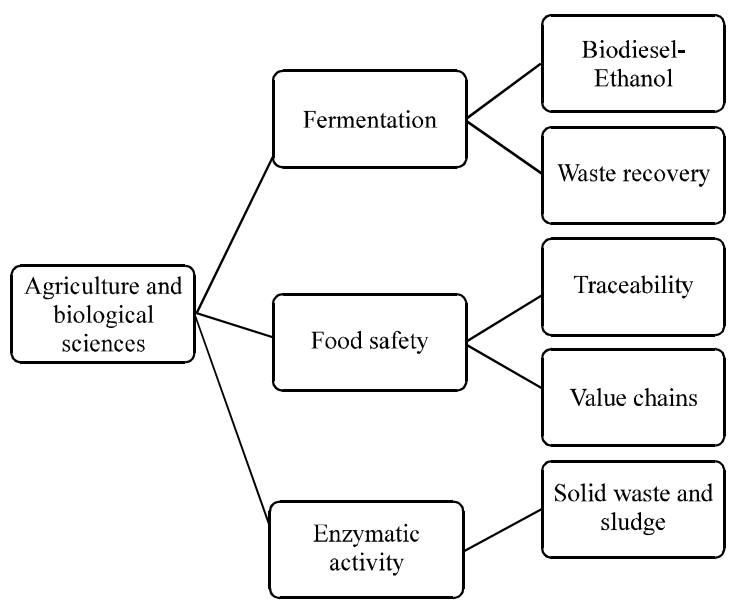

Fig. 2: Research trends for agriculture and life sciences

Faced with food security, research in the area of traceability is based on ICT solutions for the agro-industrial sector with more quantity and quality of information, improving consumer expectations in terms of food safety and product quality. In the case of the sub-area of value chains, the research focuses on the satisfaction of the final consumer and his perception of value in the agro-industrial product consumed. In the same way, the focus is on the study of small-scale production and fragmentation of markets that breaks the value chains.

As for the subarea of enzymatic activity, recovery of solid waste and sludge through hydrolytic enzymes is observed which allow the removal of fats and oils for recovery through other low-cost after-treatment applied to agroindustrial waste.

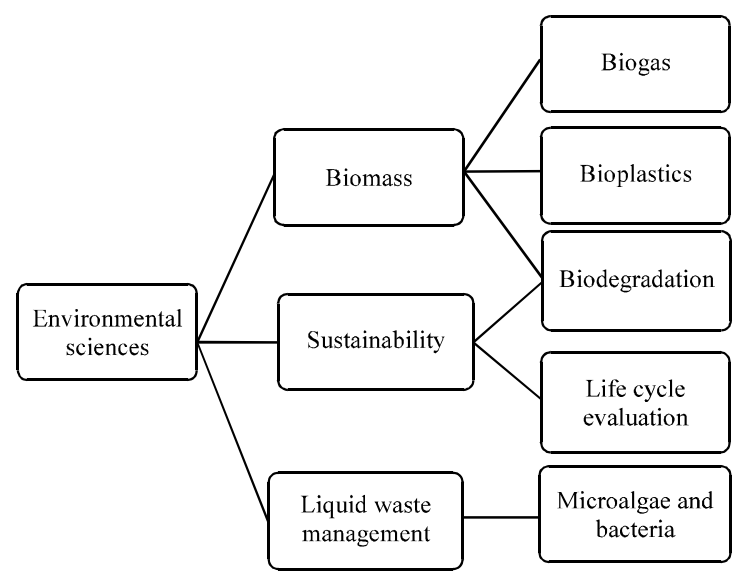

Fig. 3: Research trends for the environmental science subject area

For the environmental sciences area, two sub-areas of research are highlighted: biomass, sustainability and liquid waste management (Fig. 3). In terms of biomass, the biogas sub-area focuses on anaerobic digestion with the application of algae through the evaluation of the biochemical potential of methane to increase its yield.

Regarding bioplastics, the focus of research is the production of "bioplastic" polyhydroxyalkanoate. This polymer has the property of degradability, based on the waste treatment of the paper industry and the acidification through bacteria in different stages of the waste. Biodegradation is oriented to the kinetic modeling of waste biodigestion and biodegradation by microorganisms such as Burkholderia cepacia and halophilic organisms. 


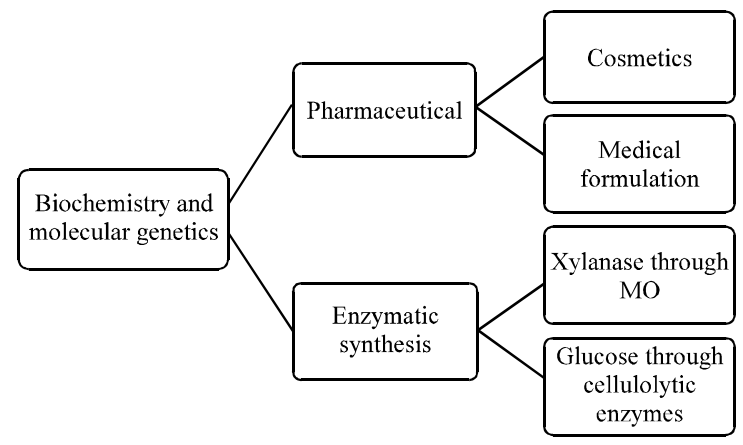

Fig. 4: Research trends for biochemistry and molecular genetics

For the sustainability sub-area, the evaluation of life cycles is oriented towards the evaluation of value chains and the supply of agroindustrial products for the identification of critical points of environmental impact that should be intervened in order to improve the productivity and sustainability of the productive processes.

Lastly, in the sub-area of liquid waste management, the research of microalgae and bacteria for the production of biofuels through the aggregation of microalgae biomass and Chlorella sorokiniana batteries stands out. The combined treatment facilitates the elimination of lipid load of liquid waste.

It is estimated that the production of algae is ten times higher than the plants cultivated on land and presents independence from land for cultivation. The biomass of algae is rich in lipids, proteins and starch which can be converted into energy using thermal, biochemical and esterification of fat acids to produce biodiesel and even could be used for the production of second generation biofuels such as methane.

Regarding the thematic area of biochemistry and molecular genetics (Fig. 4), two sub-areas of research stand out: pharmaceutical and enzymatic synthesis. For the pharmaceutical sub-area, the research focuses on the identification and characterization of active ingredients of agricultural raw materials and agroindustrial waste for the production of cosmetic products, among the active principles are phenols and carotenoids of mainly coffee and antioxidant polyphenols of avocado pericarp, among others.

Research in medical formulation is aimed at obtaining phenolic acids such as caffeic acid, p-coumaric acid and ferulic acid by different routes. The assays were performed using eruloyl esterase derived from Aspergillus niger. The waste used to obtain these principles with pharmaceutical potential were coffee pulp, apple pulp and wheat straw.

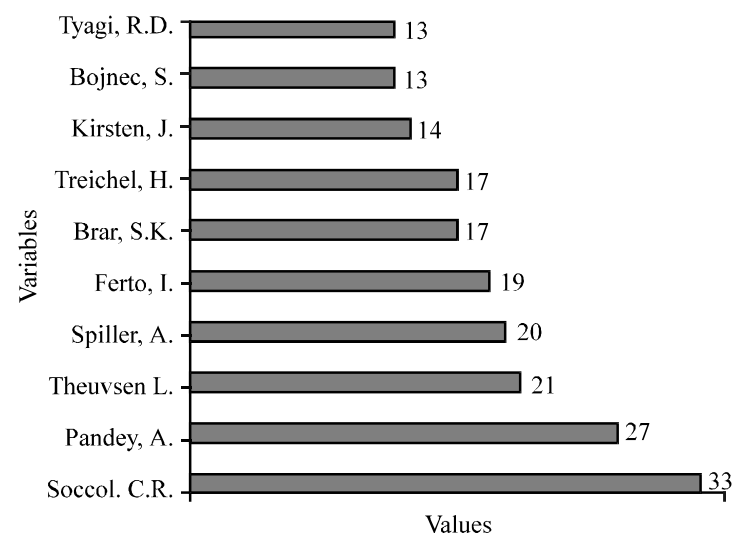

Fig. 5: Outstanding researchers in the agroindustrial sector (2005-2015)

For the enzyme synthesis sub-area, there is special interest in obtaining Xylanase from agroindustrial waste, by means of microorganisms such as Aspergillus niger, Aspergillus orizae, Aspergillus japonica, Penicillium canescens, Talaromyces and Bacillus circulans. The Xylanases belong to the pentosanas, a group of enzymes that decompose components of the matrix of the cell wall of plants and is used in bakery mainly as a baking enzyme to improve dough qualities (workability, stability) and to optimize the product (stabilization of the bark and volume).

Outstanding researchers in scientific production: The scientific production related to the agroindustrial sector (Fig. 5) is led by the scientist Carlos Ricardo Soccol from the Federal University of Parana with 33 publications related to agro-industry. His main area of research is biochemistry and molecular genetics (Medina et al., 2015; Costa et al., 2015; Pereira et al., 2015; Medina-Macedo et al., 2015; Moreira et al., 2015; Liguori et al., 2015).

The second researcher with the most publications is Ashok Pandey from the biotechnology division of the National Interdisciplinary Institute of Science and Technology in Thiruvananthapuram, India, co-researcher of Soccol in some publications. His research has focused on the evaluation of fermentation methods and obtaining antioxidants (Khare et al., 2015; Prabisha et al., 2015; Sajitha et al., 2015; Sajna et al., 2015; Sindhu et al., 2015; Varsha et al., 2015; Vivek et al., 2016).

Finally, the scientist Ludwig Theuvsen, from the Department of Agricultural Economics and Rural Development of the Gottingen University in Germany has 21 publications. His specific area of research is the agroindustrial value chains (Gollisch andTheuvsen, 2015; 


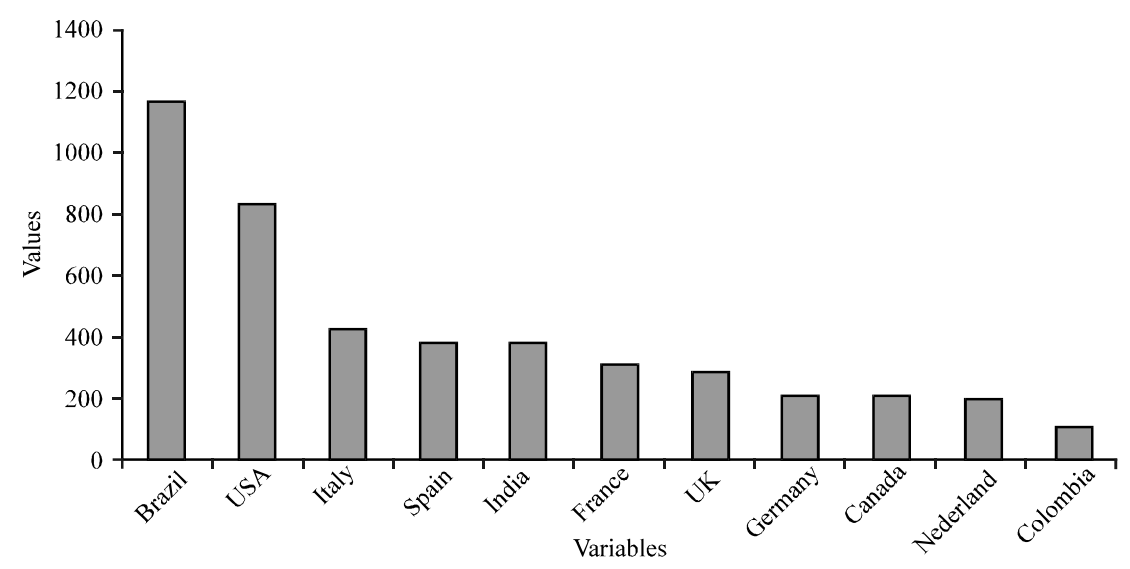

Fig. 6: Countries with scientific production for the agro-industrial sector (2005-2015)

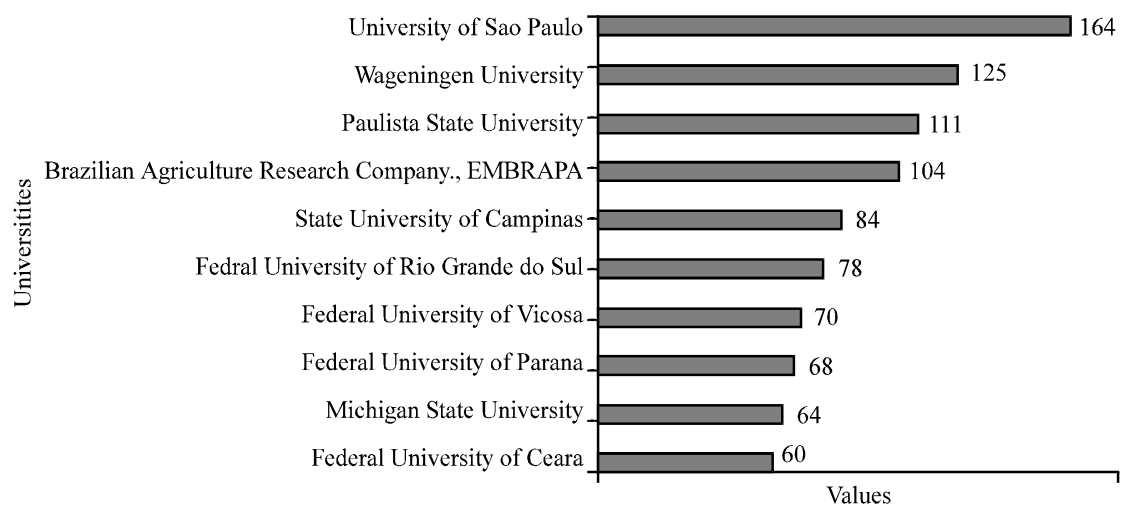

Fig. 7: Institutions with scientific production (2005-2015)

Guenther-Lubbers et al., 2016; Heise and Theuvsen, 2015a, b; Naether and Theuvsen, 2015; Schulte and Theuvsen, 2015).

Finally, nationally, Piedad Ganan R. stands out from the University Pontificial Bolivarian a Medellín with 6 publications and is particularly involved in obtaining nanofibers and nanocomposites from agroindustrial waste (Andrade et al., 2015; Alvarez-Lopez et al., 2014; Castro et al., $2015 \mathrm{a}$, b; Correa et al., 2015; Montoya et al., 2014; Osorio et al., 2014).

Countries with the highest number of publications: Among the countries with the highest number of related publications, Brazil, the United States and Italy stand out. In the case of Brazil, the 1,169 publications are directly related to Empresa Brasileira de Pesquisa Agropecuaria-Embrapa, the University of Sao Paulo-USP and the State University Paulista-UNESP (Fig. 6).

In the case of the United States with 833 publications, publications related to Michigan State University, Purdue University and Cornell University stand out. Regarding the linkage and networking in the case of the United States, there are 34 publications with Canadian researchers. Finally, Colombia appears in the 16th place with 108 publications during the period 2005-2015.

Outstanding institutions with scientific production: The University of Sao Paulo, the University of Wageningen and the Sao Paulo State University are the main institutions related to scientific production. As can be seen, $80 \%$ of the institutions in the top 10 are from Brazil, one is from the Netherlands and the other from the United States. The National University of Colombia is ranked 17th with 36 publications (Fig. 7).

\section{CONCLUSION}

From the results of this research, it can be concluded that the scientific production related to the agroindustry is concentrated in developed countries such as the United States, Italy, Spain, Great Britain, Germany, Canada, among others. However, Brazilis the undisputed leader as 
representative of the emerging countries along with India, located in the 5 th place. There is also a highly growing trend in scientific production in the period studied which exceeds the barrier of 1,000 products for 2015 with an incremental dynamic for 2016 .

Facing the fields of research in agro-industry, three major areas of research stand out: agriculture and biological sciences, environmental sciences and chemistry and molecular genetics. For the area of agriculture and biological sciences, the three main sub-areas of research are fermentation, food safety and enzymatic activity. For the area of environmental sciences, two sub-areas of research are highlighted: biomass, liquid waste sustainability and management. Regarding the area of biochemistry and molecular genetics, two sub-areas of research stand out: pharmaceutical and enzymatic synthesis. In general, the usefulness of byproducts and compounds of agricultural products for industrial use are widely researched with a high level of complexity and specialization.

Regarding the most productive researchers in the different areas of research, it should be noted that of the three researchers that accumulate the most scientific products, two correspond to emerging countries such as Brazil and India while the third corresponds to Germany. The above seems to correspond to the high potential producer of raw materials of agricultural origin of the two leading countries mentioned which are rapidly seeking the incursion of added values.

\section{REFERENCES}

Alvarez-Lopez, C., O.J. Rojas, B. Rojano and P. Ganan, 2014. Development of self-bonded fiberboards from fiber of leaf plantain: Effect of water and organic extractives removal. Bioresources., 10: 672-683.

Andrade, R.D., O. Skurtys, F. Osorio, R. Zuluaga and P. Ganan et al., 2015. Rheological and physical properties of gelatin suspensions containing cellulose nanofibers for potential coatings. Food Sci. Technol. Intl., 21: 332-341.

Anonymous, 2014. Society for competitive intelligence professionals frequently asked questions. Strategic and Competitive Intelligence Professionals, San Antonio, Texas, USA.

Castro, C., N. Cordeiro, M. Faria, R. Zuluaga and J.L. Putaux et al., 2015a. In-situ glyoxalization during biosynthesis of Bacterial cellulose. Carbohydr. Polym., 126: 32-39.
Castro, C., R. Zuluaga, O.J. Rojas, I. Filpponen and H. Orelma et al., 2015b. Highly percolated poly (Vinyl alcohol) and bacterial nanocellulose synthesized in situ by physical-crosslinking: Exploiting polymer synergies for biomedical nanocomposites. RSC. Adv., 5: 90742-90749.

Correa, C.E., S. Betancourt, A. Vazquez and P. Ganan, 2015. Wear resistance and friction behavior of thermoset matrix reinforced with Musaceae fiber bundles. Tribol. Intl., 87: 57-64.

Costa, J.D.L., A.L.L. da Silva, M.C.J. Bier, G.E. Brondani and A.L. Gollo et al., 2015. Callus growth kinetics of physic nut (Jatropha curcas L.) and content of fatty acids from crude oil obtained in vitro. Appl. Biochem. Biotechnol., 176: 892-902.

Daim, T.U., G. Rueda, H. Martin and P. Gerdsri, 2006. Forecasting emerging technologies: Use of bibliometrics and patent analysis. Technol. Forecasting Soc. Chang., 73: 981-1012.

Du Toit, A.S.A., 2013. Comparative study of competitive intelligence practices between two retail banks in Brazil and South Africa. J. Intell. Stud. Bus., 3: 30-39.

Garcia, A.B., J.M.M. Chaus and J.F.M. Ortega, 2016. [Methodology to evaluate the functions and products of technological surveillance and competitive intelligence (VT/IC) and its implementation through the web (In Spanish)]. Inf. Prof., 25: 103-113.

Gimenez-Toledo, E. and A. Roman, 2001. [Technology watch and competitive intelligence: Concepts, professionals, services and information sources (In Spanish)]. Inf. Prof., 10: 11-20.

Gollisch, S. and L. Theuvsen, 2015. Risk management in the agricultural trade: Characteristics, challenges, implications. Rep. Agric. Band, 93: 1-16.

Guenther-Lubbers, W., H. Bergmann and L. Theuvsen, 2016. Potential analysis of the biogas production-as measured by effects of added value and employment. J. Cleaner. Prod., 129: 556-564.

Heise, H. and L. Theuvsen, 2015b. German farmer's conception of animal welfare: A questionnaire survey. J. Austr. Soc. Agric. Econ., 25: 117-126.

Heise, V.H. and L. Theuvsen, 2015a. [Biological functioning, natural living or welfare-quality: Investigations on animal welfare of German farmers (In German)]. Rep. Agric., 93: 1-20.

Khare, S.K., A. Pandey and C. Larroche, 2015. Current perspectives in enzymatic saccharification of lignocellulosic biomass. Biochem. Eng. J., 102: 38-44. 
Lee, J., C. Kim and J. Shin, 2017. Technology opportunity discovery to $\mathrm{R}$ and $\mathrm{D}$ planning: Key technological performance analysis. Technol. Forecasting Soc. Change, 119: 53-63.

Lee, S., B. Yoon and Y. Park, 2009. An approach to discovering new technology opportunities: Keyword-based patent map approach. Technovation, 29: 481-497.

Lee, Y., S.Y. Kim, I. Song, Y. Park and J. Shin, 2014. Technology opportunity identification customized to the technological capability of SMEs through two-stage patent analysis. Scientometrics, 100: 227-244.

Liguori, R., C.R. Soccol, L.P.D.S. Vandenberghe, A.L. Woiciechowski and V. Faraco, 2015. Second generation ethanol production from brewer's spent grain. Energies, 8: 2575-2586.

Medina, J.D.C., A. Woiciechowski, A.Z. Filho, M.D. Noseda and B.S. Kaur et al., 2015. Lignin preparation from oil palm empty fruit bunches by sequential acid/alkaline treatment-a biorefinery approach. Bioresour. Technol., 194: 172-178.

Medina-Macedo, L., A.M. Sebbenn, A.E.B. Lacerda, J.Z. Ribeiro and C.R. Soccol et al., 2015. High levels of genetic diversity through pollen flow of the coniferous Araucaria angustifolia: A landscape level study in Southern Brazil. Tree Gen. Genomes, Vol. 11, 10.1007/s11295-014-0814-1

Montoya, U., R. Zuluaga, C. Castro, S. Goyanes and P. Ganan, 2014. Development of composite films based on thermoplastic starch and cellulose microfibrils from Colombian agroindustrial wastes. J. Thermoplast. Compos. Mater, 27: 413-426.

Moreira, N.L., L.F.D. Santos, C.R. Soccol and H.H. Suguimoto, 2015. Dynamics of ethanol production from deproteinized whey by Kluyveromyces marxianus: An analysis about buffering capacity, thermal and nitrogen tolerance. Braz. Arch. Bio. Technol., 58: 454-461.

Naether, M. and L. Theuvsen, 2015. Animal-welfare friendly control of epizootics does not have to be expensive-an analysis using the example of classical swine fever. Vet. Surv., 70: 471-477.

Osorio, M.A., D. Restrepo, J.A. Velasquez-Cock, R.O. Zuluaga and U. Montoya et al., 2014. Synthesis of thermoplastic starch-bacterial cellulose nanocomposites via in situ fermentation. J. Braz. Chem. Soc., 25: 1607-1613.

Palop, F. and J.M. Vicente, 1999. [Technological Surveillance and Competitive Intelligence: Its Potential for the Spanish Company]. COTEC, Europe, Pages: 116 (In Spanish).
Pere, E. and R. Maspons, 2001. [From Technological Surveillance to Competitive Intelligence]. Pearson Educacion, London, England, ISBN: 9788420530574 , Pages: 165 (In Spanish).

Pereira, G.V.D.M., E. Neto, V.T. Soccol, A.B.P. Medeiros and A.L. Woiciechowski et al., 2015. Conducting starter culture-controlled fermentations of coffee beans during on-farm wet processing: Growth, metabolic analyses and sensorial effects. Food Res. Intl., 75: 348-356.

Porter, A.L. and S.W. Cunningham, 2005. Tech Mining: Exploiting New Technologies for Competitive Advantage. Wiley, Hoboken, New Jersey, USA., ISBN:9780471475675, Pages: 384.

Prabisha, T.P., R. Sindhu, P. Binod, V. Sankar and K.G. Raghu et al., 2015. Production and characterization of PHB from a novel isolate Comamonas sp. from a dairy effluent sample and its application in cell culture. Biochem. Eng. J., 101: 150-159.

Ramirez-Calvo, P., A.C. Trivino, A. Berges-Garcia, J.M. Meneses-Chaus and J.F. Martinez, 2013. [New technologies in competitive intelligence analysis: Practical cases (In Spanish)]. Inf. Prof., 22: 448-454.

Sajitha, S., J. Vidya, P. Binod and A. Pandey, 2015. Cloning and expression of 1-asparaginase from $E$. coli in eukaryotic expression system. Biochem. Eng. J., 102: 14-17.

Sajna, K.V., R.K. Sukumaran, L.D. Gottumukkala and A. Pandey, 2015. Crude oil biodegradation aided by biosurfactants from Pseudozyma sp. NII 08165 or its culture broth. Bioresour. Technol., 191: 133-139.

Sandino-Vargas, E., 2014. A strategy to meet: UK is trying to innovate in terms of competitiveness, 1998-2005. Jose Mar. Cordova Gen. Sci. J., 12: 205-258.

Schulte, M. and L. Theuvsen, 2015. Influence of incentive system design on individual farm performance: A survey in the German strawberry and asparagus sectors. Eur. J. Hortic. Sci., 80: 249-259.

Sindhu, R., E. Gnansounou, A. Pandey and P. Binod, 2015. A novel crude glycerol assisted surfactant pretreatment strategy of chili post-harvest residue for bioethanol production. Biofuels, 6: 383-390.

Vargas, M.I.R., 2015. Determinant factors for small business to achieve innovation, high performance and competitiveness: Organizational learning and leadership style. Proc. Soc. Behav. Sci., 169: 43-52.

Varsha, K.K., L. Devendra, G. Shilpa, S. Priya and A. Pandey et al., 2015. 2,4-Di-tert-butyl phenol as the antifungal, antioxidant bioactive purified from a newly isolated Lactococcus sp. Intl. J. Food Microbiol., 211: 44-50. 
Villarroel, G.C., A. Comai, V. Karmelic-Pavlov, O.A. Fernandez and V.C. Arriagada, 2015. [Design and implementation of a technological surveillance and competitive intelligence unit (In Spanish)]. Interciencia, 40: 751-757.
Vivek, N., A. Pandey and P. Binod, 2016. Biological valorization of pure and crude glycerol into 1, 3-propanediol using a novel isolate Lactobacillus brevis N1E9. 3.3. Bioresour. Technol., 213: 222-230. 